\title{
Refraining from Seeking Mental Healthcare and Poorer Mental Well- Being: A Longitudinal Population-Based study on Men in Sweden
}

\section{Sara Olsson ( $\square$ sara.olsson@gu.se)}

Institute of Medicine, University of Gothenburg https://orcid.org/0000-0002-3213-2310

Bo Burström

Department of Global Public Health, Karolinska institutet

\section{Gunnel Hensing}

Institute of Medicine, University of Gothenburg

Jesper Löve

Institute of Medicine, University of Gothenburg

\section{Research article}

Keywords: Longitudinal studies, mental health services, unmet need, barriers to care, health behaviours, patient satisfaction, mental disorders, depression, gender, masculinity

Posted Date: July 20th, 2020

DOI: https://doi.org/10.21203/rs.3.rs-42827/v1

License: (1) This work is licensed under a Creative Commons Attribution 4.0 International License. Read Full License 


\section{Abstract}

Background: Depression and anxiety disorder contribute to a significant part of the disease burden among men, yet many men refrain from seeking care or receive insufficient care when they do seek it. This is plausibly detrimental to men's mental well-being, but there is a lack of population-based research to confirm this. This study investigated 1) if men who had refrained from seeking mental healthcare had poorer mental well-being than those who sought care, 2) if those who sought care but perceived it as insufficient had poorer mental well-being than those who perceived care as sufficient, and 3) if these differences persisted over time.

Methods: This longitudinal study used questionnaire data from a population-based sample of 1240 men, aged 19-64 years, in Sweden. Having refrained from seeking mental healthcare, or perceiving the care as insufficient, at any time in life, was assessed in a questionnaire, 2008. Current mental well-being was assessed in both 2008 and 2009 using mean scores on the WHO (Ten) Well-being Index, with a lower score indicating poorer mental well-being. Group differences were calculated using t-tests and multivariable linear regression analysis.

Results: Of the men who had perceived a need for mental healthcare, $37 \%$ refrained from seeking such care. They had lower mental well-being scores in 2008, compared to those who sought care. Of those seeking care, 29 \% perceived it as insufficient. They had lower mental well-being scores in 2008, compared to those who perceived the care as sufficient, but this was not statistically significant when controlling for potential confounders in the regression analysis. There were no differences in mental well-being scores based on care-seeking or perceived care-sufficiency in 2009 .

Conclusions: This population-based study provides some empirical support for the hypothesis that refraining from seeking mental healthcare, or perceiving the care as insufficient, is detrimental to men's mental well-being. However, the lack of persistent differences contradicts this hypothesis. The results highlight the need for more research, using larger population-based samples of men, and longer follow-up periods. This should be combined with efforts to increase men's mental healthcare-seeking and to provide mental healthcare that is perceived as sufficient.

\section{Introduction}

Common mental disorders such as depression and anxiety disorders have a high prevalence (1), and account for $4 \%$ of the disease burden among men aged 15-49 years in Western Europe, according to the Global Burden of Disease Study (2). Especially if untreated, these disorders are often longstanding, recurrent, and have a negative effect on individual function and productivity (3-5). There is consistent evidence for the benefit of receiving treatment, even for mild to moderate depression and anxiety disorders $(4,5)$. Remission or reduction of symptoms can be attained by psychotherapy, pharmacotherapy, or a combination of both $(4,5)$. Yet a large proportion of men refrain from seeking mental healthcare. For example, a population-based study from Sweden showed that $57 \%$ of the men with current depression and/or anxiety disorder had not sought care during the past year (6).

Refraining from seeking mental healthcare has been suggested to be detrimental for men's mental well-being on a population level (7-11). Yet empirical data is lacking. For example, men's reluctance to seek care has been hypothesised to be one of the explanations for men's higher risk for premature death and suicide (7). This is partly due to an assumed negative effect of later diagnosis and treatment $(8,9,12)$ and a proposed connection to other risk behaviours e.g. higher alcohol consumption (7), reckless driving (10), and workaholism (9). These behaviours have partly been explained by masculinity norms encouraging men to deal with mental health problems in ways that are harmful to their health, but may benefit men's position in social hierarchies (7). Some empirical research indicates detrimental outcomes of refraining from seeking mental healthcare among men, but these do not focus specifically on mental healthcare-seeking; rather, they have a broader perspective on masculinity norms and suicide $(13,14)$. For example, a population-based study identified self-reliance, defined as being reluctant to seek help, as a risk factor for suicidal thinking among men (13). A qualitative study on men who had attempted suicide found that due to masculinity norms that encouraged non-disclosure of distress these men had opted for suicide instead of seeking care (14). Although most men who refrain from seeking mental healthcare do not deteriorate into suicidality due to having milder conditions $(15,16)$ they may still benefit from treatment $(4,5)$. Based on the suggested risks for poorer health and risk behaviours among men who refrain from seeking mental healthcare (7-11), and the benefits of receiving treatment $(4,5)$, one might assume that men who refrain from seeking mental healthcare will have poorer subsequent mental well-being than those who seek care. However, there is a lack of evidence from population-based longitudinal studies to confirm this hypothesis.

Furthermore, a limitation of previous research is that most studies have focused on men's reluctance to seek mental healthcare (17), overlooking the fact that many men do seek it. However, many care-seeking men do not receive sufficient care. A multi-country study from high-income countries shows that among men and women who sought mental healthcare with symptoms corresponding to major depression, only half received treatment meeting minimally adequate standards (18). Qualitative studies have also shown that even among care-seeking men, many are sceptical about treatment, minimise their symptoms, and are unwilling to disclose distress, behaviours shown to be related to masculinity norms $(14,17,19)$. Clinical and epidemiological studies have found that men have a higher likelihood for under-diagnosis of depression $(20,21)$, under-treatment with antidepressants, (22), insufficient follow-up during sick leave for mental diagnoses (23) and of perceiving the mental 
healthcare as insufficient, than do women (24). Possibly, this indicates poorer quality of mental healthcare for men than women. Indicators of poor quality of care, such as poor adherence to treatment, and adverse events in care situations, are consistently associated with perceived sufficiency of care (25). Based on the association between quality of care and perceived sufficiency of care, one might assume that men who sought mental healthcare, but perceived it as insufficient, would have poorer subsequent mental well-being than those who perceived the care as sufficient. To our knowledge, no present study investigates this hypothesis using longitudinal data from a population sample of men.

Considering that men's unmet need for mental healthcare occurs on multiple steps on the pathway to mental healthcare (24), there is a need for epidemiological studies considering how both refraining from seeking care, and perceiving the care as insufficient when seeking it, are related to subsequent poorer mental well-being. Poorer mental well-being based on unmet need may persist or occur over time, as depression and anxiety disorders are often longstanding and recurrent $(3,4,26)$. Therefore, there is a particular need for longitudinal studies. Also, previous research on men's mental healthcare-seeking is primarily from the US, Australia, and the UK, with few studies from the Nordic countries (27). Sweden is interesting considering that mental healthcare at primary care and specialised care units is included in the universal health care system (28). In a population-based sample of men in Sweden, this longitudinal study investigated 1) if men who had refrained from seeking mental healthcare had poorer mental well-being than those who sought care, 2) if those who sought care but perceived it as insufficient had poorer mental well-being than those who perceived care as sufficient, and 3) if these differences persisted over time. Mental well-being was measured at two time points, one year apart, time 1 (T1) and time 2 (T2). The study design and hypotheses are illustrated in Fig. 1. The following hypotheses were tested:

1. Men who have refrained from seeking mental healthcare will have poorer mental well-being at both T1 (hypothesis A1) and T2 (hypothesis A2), compared to men who sought care when perceiving a need.

2. Men who have sought mental healthcare but perceived the care as insufficient will have poorer mental well-being at both T1 (hypothesis B1) and T2 (hypothesis B2), compared to those who perceived it as sufficient.

\section{Methods}

\section{Study design and participants}

The longitudinal study was based on two questionnaires and sociodemographic registry data from the Health Assets Project (HAP) (29), with a general population sample of men in Region Västra Götaland, Sweden. The region has 1.7 million urban and rural inhabitants, constituting 17\% of Sweden's population. A random general population-based sample of men and women, aged 19-64 years, was extracted by Statistics Sweden and invited to participate $(n=7984$, Fig. 2). The invited men and women received the first postal questionnaire, referred to as T1, between 15 April to 30 June 2008 (30). The T1 questionnaire comprised questions on mental healthcare-seeking at any time in life, mental and physical persistent illness, sociodemographic factors, and an index on mental well-being. A previous analysis of non-participation showed that those born outside the Nordic countries, those with low income, young persons, men, and those who were single were less likely to participate at T1 (31). Previously, several studies have been published based on the T1 questionnaire and the population-based sample, e.g., a recently published study showing gender and education-based differences in unmet need for mental healthcare (24). The current study included men only. Of the 4086 persons registered as men by Statistics Sweden, $44 \%(n=1793)$ participated at T1, and consequently were included in this study (Fig. 2$)$. This group received a follow-up questionnaire between 21 September and 12 December 2009, referred to as T2. Both questionnaires were followed by two reminders. The T2 questionnaire comprised an index on mental well-being. Of the 1793 men who participated at T1, 23\% were lost to follow-up at T2. In total, $34 \%$ of the invited men participated at both T1 and T2 ( $n=1283$, Fig. 2$)$. Of those, 11 participants were excluded due to missing data on mental healthcare-seeking. Also, 131 participants were excluded due to missing data on the item on mental well-being at T1 and/or T2 ( $n=74$ had missing data at T1, $n=66$ at T2, and $n=9$ at both T1 and T2). Consequently, the final study sample comprised 1240 men, i.e. participants with data from both T1 and T2 (Fig. 2). The time elapsed between T1 and T2 ranged from 14.5 to 20 months.

\section{Exposure variables}

Perceived need for mental healthcare and seeking mental healthcare at any time in life was assessed using the T1 questionnaire, based on the question "Have you at any time felt so mentally unwell that you felt a need to seek care?" The study sample was divided into three categories based on the response alternatives ("yes", "yes, but did not seek", and "no"): 1) care-seekers, who had perceived a need for mental healthcare and sought care, 2) non-care-seekers, who had perceived a need for mental healthcare but refrained from seeking it, and 3) non-need-perceivers, who had not perceived a need for mental healthcare. In addition, care-seekers were divided into two categories based on the follow-up question "Do you think you received the care that you needed?" with the response alternatives "yes" (i.e. sufficient care-perceivers) and "no" (i.e. insufficient care-perceivers, Fig. 1). Data on where care-seekers had sought care is presented elsewhere (24).

\section{Potential confounders}


The association between poorer mental well-being and refraining from seeking mental healthcare or perceiving the care as insufficient may be confounded by sociodemographic and health variables. For example, lower education is associated with both refraining from seeking mental healthcare (24), and poorer mental well-being (32). Poor health, e.g. having a persistent mental illness is associated with seeking mental healthcare (33), perceiving the care as insufficient $(34,35)$, and poorer mental well-being (36-38). Based on this, potential confounders chosen were education, country of birth, age, persistent physical illness, and persistent mental illness. These variables were measured at T1. Age (categorised into 19-30, 31-50, and 51-64 years) and country of birth (dichotomised into Nordic versus non-Nordic country based on nine categories: Sweden, other Nordic countries, other European countries, Africa, Asia, North America, South America, Oceania, and others) were based on register data from Statistics Sweden. The level of completed education was based on questionnaire data (categorised into primary education or less, secondary education, and university education, based on six response alternatives). Persistent illness was measured using questionnaire data on whether the respondent had any persistent disease, illness, or disability, followed by a checklist of categories (e.g., cardiovascular, neurological, and mental illnesses). Respondents choosing "mental illness" were considered to have persistent mental illness. Those choosing one or more physical illnesses categories were considered to have persistent physical illness.

\section{Outcomes}

Mental well-being was assessed both at T1 and T2 using the WHO (Ten) Well-being Index (WHO-10) (39). The index comprises ten items covering depression, anxiety, energy, and positive well-being in the previous week. Each item has four response alternatives ranging from "never" (i.e. 0) to "all the time", (i.e. 3), giving a total score of 0-30. A lower score indicates lower mental well-being and has been found to correspond to depression (36-38), and suicidality (38). For example, cut-offs $\leq 8$, and $\leq 12$ have been found to correspond to depression according to the Schedules for Clinical Assessment in Neuropsychiatry and Major Depression Inventory, respectively (36, 37). WHO-10 is suitable both as a screening tool for depression, as an outcome measure of treatment effects, and for comparison of mental well-being between population groups and over time (38). The Swedish version of the WHO-10, used here, has shown good reliability and validity (40).

\section{Statistical analyses}

Descriptive statistics of health and sociodemographic characteristics at T1 were obtained by calculating frequencies ( $n$ ), proportions (\%), and proportional differences using Pearson's $\mathrm{Chi}^{2}$ test. To investigate potential differences in mental well-being scores between 1 ) non-care-seekers versus care-seekers, and 2) insufficient-care-perceivers versus sufficient care-perceivers, differences in means were calculated using independent sample t-tests, and multivariable linear regression analyses. The analyses were conducted at T1 and T2, separately. To explore if these potential differences were consistent across subgroups, t-tests were stratified by potential confounders. Multivariable linear regression analysis was used to investigate differences in mental well-being scores between the groups while controlling for potential confounders. All relevant assumptions for multivariable linear regression analyses were met (41). Potential confounders were entered into multivariable models in steps: Model 1 included sociodemographic variables, and Model 2 added health variables. The analyses are presented as unstandardised beta-coefficients (B) with a $95 \%$ confidence interval, and R squares (R2).

Drop-out analysis was conducted by comparing characteristics of the participants lost to follow-up at T2, versus the participants, using Pearson's $\mathrm{Chi}^{2}$ test and independent sample t-tests. Such analysis was also performed to compare the characteristics of those who were excluded due to missing data on the WHO-10 at T1 and/or T2, versus the final study sample. To investigate if the exclusion of these participants changed the results presented in this paper, sensitivity analyses were conducted where all analyses were performed for a sample including those 131 with missing data on WHO-10 $(n=1371)$. For all statistical analyses, the alfa level was set at $p<0.05$. All statistical analyses were conducted using IBM SPSS Statistics, version 25.

\section{Results}

\section{Loss to follow-up and analyses of missing data}

Of the 1793 participants at T1, 411 were lost to follow-up at T2 (Fig. 2). These were more likely to be younger, to have secondary education (versus university education), to be born outside the Nordic countries, to have persistent mental illness, poorer mental well-being, and to have perceived a need for mental healthcare at some time in life, compared to the T2 participants $(p<0.05)$. No statistically significant differences in mental healthcare-seeking, or perceived care-sufficiency were observed (see Supplementary Table 1, Additional file 1). The group with missing data on WHO-10 were more likely to be older, to be born outside the Nordic countries, and to have primary education (versus secondary and university education), compared to the study sample $(p<0.05)$. No statistically significant differences in persistent mental or physical illness, mental well-being, perceived need for mental healthcare, mental healthcare-seeking, or perceived care-sufficiency were observed (see Supplementary Table 2, Additional file 2). 


\section{Characteristics of the study sample}

Of the study sample of 1240 men, $24 \%(n=293)$ reported that they had perceived a need for mental healthcare at some time in life. Of those, $37 \%$ had refrained from seeking care (non-care-seekers, Table 1). A higher proportion of non-care-seekers were younger, and did not have a persistent mental illness, compared to care-seekers $(p<0.05)$. Among the care-seekers, $29 \%$ reported that they had received insufficient mental healthcare when seeking it (insufficient care-perceivers, Table 1). A higher proportion of insufficient-care-perceivers were younger, compared to sufficient-careperceivers $(p<0.05)$.

Table 1

Characteristics of the sample of men a.

\begin{tabular}{|c|c|c|c|c|c|c|c|}
\hline & & \multirow[t]{2}{*}{$\begin{array}{l}\text { Total } \\
\text { sample } \\
\mathrm{N}=1240\end{array}$} & $\begin{array}{l}\text { Non-need- } \\
\text { perceivers } \\
\mathrm{n}=947^{\mathrm{b}}\end{array}$ & \multicolumn{2}{|c|}{$\begin{array}{l}\text { Need-perceivers by care- } \\
\text { seeking }\end{array}$} & \multicolumn{2}{|c|}{$\begin{array}{l}\text { Care-seekers by perceived care-sufficiency } \\
n=182\end{array}$} \\
\hline & & & & $\begin{array}{l}\text { Non-care- } \\
\text { seekers }\end{array}$ & $\begin{array}{l}\text { Care- } \\
\text { seekers }\end{array}$ & $\begin{array}{l}\text { Insufficient care- } \\
\text { perceivers }\end{array}$ & $\begin{array}{l}\text { Sufficient care- } \\
\text { perceivers }\end{array}$ \\
\hline & & & & $\begin{array}{l}\mathrm{n}=109^{\mathrm{b}} \\
(37 \%)\end{array}$ & $\begin{array}{l}n=184^{b} \\
(63 \%)\end{array}$ & $\begin{array}{l}n=52^{c} \\
(29 \%)\end{array}$ & $\begin{array}{l}\mathrm{n}=130^{\mathrm{c}} \\
(71 \%)\end{array}$ \\
\hline Time 1, 2008 & & $\mathrm{n}$ & $\%^{d}$ & $\% d$ & $\%^{d}$ & $\%^{d}$ & $\%^{d}$ \\
\hline \multirow[t]{3}{*}{ Age, years } & $19-30$ & 221 & 18 & 24 & 14 & 21 & 12 \\
\hline & $31-50$ & 567 & 45 & 51 & 49 & 56 & 46 \\
\hline & $51-64$ & 452 & 38 & 25 & 37 & 23 & 42 \\
\hline \multirow[t]{4}{*}{ Education } & $\begin{array}{l}\text { Primary or } \\
\text { less }\end{array}$ & 233 & 19 & 15 & 20 & 18 & 21 \\
\hline & Secondary & 568 & 46 & 57 & 43 & 41 & 43 \\
\hline & University & 428 & 35 & 28 & 37 & 41 & 36 \\
\hline & Missing & 11 & & & & & \\
\hline \multirow[t]{2}{*}{ Birth country } & Nordic & 1156 & 94 & 91 & 91 & 89 & 92 \\
\hline & Others & 84 & 6 & 9 & 9 & 12 & 8 \\
\hline \multirow{2}{*}{$\begin{array}{l}\text { Persistent physical } \\
\text { illness }\end{array}$} & Yes & 546 & 41 & 52 & 55 & 60 & 54 \\
\hline & No & 694 & 59 & 48 & 45 & 40 & 46 \\
\hline \multirow{2}{*}{$\begin{array}{l}\text { Persistent mental } \\
\text { illness }\end{array}$} & Yes & 42 & 0 & 3 & 19 & 23 & 18 \\
\hline & No & 1198 & 100 & 97 & 81 & 77 & 82 \\
\hline \multicolumn{8}{|c|}{ a By perceived need for mental healthcare, healthcare-seeking, and perceived sufficiency of healthcare } \\
\hline \multicolumn{8}{|c|}{ b Stratified by "Have you at any time in life felt so mentally unwell that you felt a need to seek care?" (No, Yes but did not seek, Yes) } \\
\hline \multicolumn{8}{|c|}{$\begin{array}{l}\text { "Stratified by "Do you think you received the care that you needed?" (No, Yes). Disperse numbers due to } \mathrm{n}=2 \text { with missing data on the } \\
\text { question. }\end{array}$} \\
\hline
\end{tabular}

\section{Comparisons of mental well-being scores using T-tests}

In the total study sample, the mean mental well-being score was 18.9 at both T1 and T2 (results not shown). Non-care-seekers had mental wellbeing scores that were 1.7 points lower at T1, compared to care-seekers (mean 14.3 versus $16.0, p=0.02$, see Table 2). When stratifying these results for sociodemographic and health variables, non-care-seekers still had lower mental well-being scores in most groups at T1, although the differences were only statistically significant for a few of them (i.e. among those with university education, no persistent physical illness, and no 
persistent mental illness). At T2, there was no longer a difference in mental well-being scores between non-care-seekers and care-seekers (mean 15.7 versus $15.8, p=0.84$ ). In line with this, there were no consistent differences in mental well-being scores between non-care-seekers and careseekers at T2 when stratifying these results (Table 2).

Among care-seekers, insufficient care-perceivers had mental well-being scores that were 2.4 points lower at T1, compared to sufficient-careperceivers (mean 14.2 versus $16.6, p=0.02$, Table 2 ). When stratifying these results for sociodemographic and health variables, insufficient careperceivers had lower mental well-being scores in all groups at T1, but the differences were only statistically significant for a few of them (i.e. among those aged 31-50 years, those with persistent physical illness, and those with persistent mental illness). At T2, there was no longer a statistically significant difference in mental well-being scores between insufficient care-perceivers and sufficient care-perceivers (mean 15.0 versus $16.1, p=0.38$, Table 2). When stratifying these results, insufficient care-perceivers had lower mental well-being scores in some of the groups at $\mathrm{T} 2$, but this was only statistically significant among those with persistent mental illness. 
Table 2

Comparison of mental well-being scores between non-care-seekers versus care-seekers, and insufficient- versus sufficient care-perceivers.

\begin{tabular}{|c|c|c|c|c|c|c|c|c|c|c|c|c|}
\hline & \multicolumn{6}{|c|}{ By mental healthcare-seeking } & \multicolumn{6}{|c|}{ By perceived sufficiency of mental healthcare } \\
\hline & \multicolumn{3}{|c|}{ Time 1, 2008} & \multicolumn{3}{|c|}{ Time 2, 2009} & \multicolumn{3}{|l|}{ Time 1, 2008} & \multicolumn{3}{|l|}{ Time 2, 2009} \\
\hline & $\begin{array}{l}\text { Non- } \\
\text { care- } \\
\text { seekers }\end{array}$ & $\begin{array}{l}\text { Care- } \\
\text { seekers }\end{array}$ & & $\begin{array}{l}\text { Non- } \\
\text { care- } \\
\text { seekers }\end{array}$ & $\begin{array}{l}\text { Care- } \\
\text { seekers }\end{array}$ & & $\begin{array}{l}\text { Insufficient } \\
\text { care- } \\
\text { perceivers }\end{array}$ & $\begin{array}{l}\text { Sufficient } \\
\text { care- } \\
\text { perceivers }\end{array}$ & & $\begin{array}{l}\text { Insufficient } \\
\text { care- } \\
\text { perceivers }\end{array}$ & $\begin{array}{l}\text { Sufficient } \\
\text { care- } \\
\text { perceivers }\end{array}$ & \\
\hline & $\begin{array}{l}\text { Mean }{ }^{1} \\
(n)\end{array}$ & $\begin{array}{l}\text { Mean }{ }^{1} \\
(n)\end{array}$ & $P *$ & Mean $^{1}$ & Mean $^{1}$ & $P *$ & $\operatorname{Mean}^{1}(n)$ & $\operatorname{Mean}^{1}(n)$ & $P^{*}$ & Mean $^{1}$ & Mean $^{1}$ & $P *$ \\
\hline Total & $\begin{array}{l}14.3 \\
(109)\end{array}$ & $\begin{array}{l}16.0 \\
(184)\end{array}$ & 0.02 & 15.7 & 15.8 & 0.84 & $14.2(52)$ & $\begin{array}{l}16.6 \\
(130)\end{array}$ & 0.02 & 15.0 & 16.1 & 0.38 \\
\hline \multicolumn{13}{|l|}{ Age, years } \\
\hline $19-30$ & $\begin{array}{l}14.5 \\
(26)\end{array}$ & $\begin{array}{l}13.2 \\
(26)\end{array}$ & 0.41 & 16.3 & 15.2 & 0.42 & $13.2(11)$ & $13.3(15)$ & 0.97 & 16.3 & 14.4 & 0.36 \\
\hline $31-50$ & $\begin{array}{l}14.5 \\
(56)\end{array}$ & $\begin{array}{l}16.4 \\
(90)\end{array}$ & 0.05 & 14.9 & 15.7 & 0.48 & $14.2(29)$ & $17.3(60)$ & 0.03 & 14.5 & 16.2 & 0.34 \\
\hline $51-64$ & $\begin{array}{l}13.9 \\
(27)\end{array}$ & $\begin{array}{l}16.5 \\
(68)\end{array}$ & 0.09 & 16.6 & 16.2 & 0.82 & $14.9(12)$ & $16.8(55)$ & 0.41 & 15.1 & 16.4 & 0.58 \\
\hline \multicolumn{13}{|l|}{ Education } \\
\hline $\begin{array}{l}\text { Primary or } \\
\text { less }\end{array}$ & $\begin{array}{l}14.7 \\
(16)\end{array}$ & $\begin{array}{l}14.7 \\
(36)\end{array}$ & 0.99 & 17.0 & 14.6 & 0.16 & $12.6(9)$ & $15.4(27)$ & 0.19 & 12.3 & 15.4 & 0.17 \\
\hline Secondary & $\begin{array}{l}14.6 \\
(60)\end{array}$ & $\begin{array}{l}15.2 \\
(78)\end{array}$ & 0.55 & 15.8 & 14.9 & 0.43 & $13.6(21)$ & $15.8(56)$ & 0.19 & 13.3 & 15.5 & 0.20 \\
\hline University & $\begin{array}{l}13.9 \\
(30)\end{array}$ & $\begin{array}{l}17.4 \\
(68)\end{array}$ & 0.01 & 14.9 & 17.5 & 0.05 & $15.2(21)$ & $18.3(46)$ & 0.06 & 17.4 & 17.4 & 0.99 \\
\hline \multicolumn{13}{|l|}{$\begin{array}{l}\text { Country of } \\
\text { birth }\end{array}$} \\
\hline $\begin{array}{l}\text { Nordic } \\
\text { country }\end{array}$ & $\begin{array}{l}14.6 \\
(99)\end{array}$ & $\begin{array}{l}15.9 \\
(168)\end{array}$ & 0.09 & 16.0 & 15.9 & 0.86 & $14.4(46)$ & $\begin{array}{l}16.4 \\
(120)\end{array}$ & 0.06 & 15.4 & 16.0 & 0.63 \\
\hline $\begin{array}{l}\text { Outside } \\
\text { Nordic }\end{array}$ & $\begin{array}{l}11.4 \\
(10)\end{array}$ & $\begin{array}{l}16.6 \\
(16)\end{array}$ & 0.06 & 11.9 & 14.9 & 0.19 & $12.8(6)$ & $18.8(10)$ & 0.09 & 12.0 & 16.7 & 0.15 \\
\hline \multicolumn{13}{|l|}{$\begin{array}{l}\text { Persistent } \\
\text { physical } \\
\text { illness }\end{array}$} \\
\hline Yes & $\begin{array}{l}14.0 \\
(57)\end{array}$ & $\begin{array}{l}14.5 \\
(101)\end{array}$ & 0.62 & 15.2 & 15.1 & 0.91 & $12.6(31)$ & $15.3(70)$ & 0.05 & 13.7 & 15.7 & 0.18 \\
\hline No & $\begin{array}{l}14.7 \\
(52)\end{array}$ & $\begin{array}{l}17.8 \\
(83)\end{array}$ & 0.00 & 16.2 & 16.7 & 0.62 & $16.6(21)$ & $18.1(60)$ & 0.29 & 16.9 & 16.5 & 0.81 \\
\hline \multicolumn{13}{|l|}{$\begin{array}{l}\text { Persistent } \\
\text { mental } \\
\text { illness }\end{array}$} \\
\hline Yes & $8.3(3)$ & $\begin{array}{l}10.7 \\
(35)\end{array}$ & 0.53 & 11.7 & 10.2 & 0.71 & 7.9 (12) & $12.1(23)$ & 0.02 & 6.0 & 12.4 & 0.01 \\
\hline No & $\begin{array}{l}14.5 \\
(106)\end{array}$ & $\begin{array}{l}17.2 \\
(149)\end{array}$ & 0.00 & 15.8 & 17.1 & 0.07 & $16.1(40)$ & $\begin{array}{l}17.6 \\
(107)\end{array}$ & 0.15 & 17.7 & 16.9 & 0.45 \\
\hline
\end{tabular}

Comparisons of mental well-being scores using multivariable linear regression analysis 
Non-care-seekers had mental well-being scores that were about two points lower at T1 in both the crude and the fully adjusted linear regression model, compared to care-seekers (Model 2, B= $-2.49,95 \% \mathrm{Cl}-3.86$ to -1.12 , Table 3 ). However, there was no statistically significant difference in scores between non-care-seekers and care-seekers at T2 (Model 2, B $=-1.11,95 \% \mathrm{Cl}-2.59$ to 0.38 , Table 3). Among care-seekers, insufficient careperceivers had mental well-being scores that were about two points lower at T1 compared to sufficient care-perceivers, in both the crude model, Model 1 (adding sociodemographic variables), and Model 2 (adding health variables). However, this difference was not statistically significant in Model $2(B=-1.70,95 \% \mathrm{Cl}-3.53$ to 0.14$)$. There was no statistically significant difference in scores between insufficient care-perceivers and sufficient care-perceivers at T2 (Model 2, B $=-0.52,95 \% \mathrm{Cl}-2.54$ to 1.50 , Table 3 ).

In sum, non-care-seekers were more likely to have lower mean mental well-being scores at T1, but not at T2, also when controlling for potential confounders. Insufficient care-perceivers were not more likely to have lower mean mental well-being scores at T1 or T2, when adjusting for potential confounders.

Table 3

Comparison of mental well-being scores, using crude and multivariable linear regression.

\begin{tabular}{|c|c|c|c|}
\hline & \multicolumn{3}{|c|}{ Non-care-seekers vs care-seekers (among need-perceivers, $n=293$ ) } \\
\hline & Crude & Model $1^{2}$ & Model $2^{3}$ \\
\hline \multicolumn{4}{|l|}{ Time 1, 2008} \\
\hline Unstandardised $\mathrm{B}^{1}$ & $-1.65(-3.08$ to -0.22$)$ & $-1.43(-2.88$ to 0.03$)$ & $-2.49(-3.86$ to -1.12$)$ \\
\hline P-value & 0.02 & 0.05 & 0.00 \\
\hline $\mathrm{R} 2$ & 0.02 & 0.04 & 0.20 \\
\hline \multicolumn{4}{|l|}{ Time 2, 2009} \\
\hline Unstandardised $\mathrm{B}^{1}$ & $-0.15(-1.68$ to 1.37$)$ & $0.00(-1.55$ to 1.54$)$ & $-1.11(-2.59$ to 0.38$)$ \\
\hline P-value & 0.84 & 1.00 & 0.14 \\
\hline \multirow[t]{2}{*}{ R2 } & 0.00 & 0.02 & 0.15 \\
\hline & \multicolumn{3}{|c|}{ Insufficient vs sufficient care-perceivers (among care-seekers, $n=182$ ) } \\
\hline \multicolumn{4}{|l|}{ Time 1, 2008} \\
\hline Unstandardised $\mathrm{B}^{1}$ & $-2.44(-4.47$ to -0.41$)$ & $-2.29(-4.35$ to -0.23$)$ & $-1.70(-3.53$ to 0.14$)$ \\
\hline P-value & 0.02 & 0.03 & 0.07 \\
\hline $\mathrm{R} 2$ & 0.03 & 0.08 & 0.28 \\
\hline \multicolumn{4}{|l|}{ Time 2, 2009} \\
\hline Unstandardised $\mathrm{B}^{1}$ & $-1.07(-3.24$ to 1.10$)$ & $-1.02(-3.23$ to 1.18$)$ & $-0.52(-2.54$ to 1.50$)$ \\
\hline P-value & 0.33 & 0.36 & 0.61 \\
\hline $\mathrm{R} 2$ & 0.01 & 0.04 & 0.21 \\
\hline \multicolumn{4}{|c|}{${ }^{1}$ Lower score indicates lower mental well-being on WHO (Ten) Well-being Index, 0-30 p. 95\% confidence intervals. } \\
\hline \multicolumn{4}{|c|}{${ }^{2}$ Adjusted for age category, education, country of birth. } \\
\hline
\end{tabular}

\section{Sensitivity analysis}

The sensitivity analyses, including those that had missing data on the WHO-10 at T1 and/or T2, were consistent with the results presented above, with one exception. The multivariable linear regression analyses showed a statistically significant association between being an insufficient careperceiver and having lower mental well-being scores at T1, also in the fully adjusted model adding health variables, in contrast to the results above (Model 2, B=-1.91, 95\% Cl -3.71 to -0.10, see Supplementary Table 3, Additional file 3). 


\section{Discussion}

This is the first longitudinal study on a population-based sample of men in Sweden investigating whether A) refraining from seeking mental healthcare, and B) perceiving care as insufficient when seeking it are detrimental to men's mental well-being (see Fig. 1). Our hypotheses were only partially supported. Firstly, we observed that $37 \%$ of the men who had perceived a need for mental healthcare had refrained from seeking care. In line with hypothesis A1, they had poorer mental well-being at T1, compared to those who sought care. However, in contrast to hypothesis A2, they did not have poorer mental well-being one year later. Secondly, we observed that $29 \%$ of the men who had sought care perceived that they had received insufficient care. In line with hypothesis B1, they had poorer mental well-being at T1, compared to those who perceived it as sufficient. However, this result was not statistically significant when adjusting for potential confounders, and the hypothesis was rejected. Likewise, insufficient care-perceivers did not have poorer mental well-being one year later, in contrast to hypothesis B2. Therefore, hypothesis A1 was confirmed, but hypotheses A2, B1, and B2 were rejected (see Fig. 1). Henceforth, we will discuss 1) the poorer mental well-being among noncare-seekers at $\mathrm{T} 1,2$ ) the indication of poorer mental well-being among insufficient-care-perceivers at $\mathrm{T} 1,3$ ) the lack of persistent differences at $\mathrm{T} 2$, and 4) the implications of the findings.

\section{Poorer mental well-being among non-care-seekers at T1}

The observed poorer mental well-being among non-care-seekers at T1 is worrying, as poor mental well-being using WHO-10 is associated with a higher likelihood for depression (36-38) and suicidality (38). This result is in line with the large body of research showing the benefits of receiving treatment $(4,5)$. More importantly, it supports the suggestion that refraining from seeking mental healthcare is detrimental for men's mental well-being also on a population level (7-11). More research is needed to confirm this finding and investigate why non-care-seekers had poorer mental well-being. However, the poorer mental well-being may reflect a risk for more severe consequences, such as premature death and suicide, and the use of maladaptive coping strategies, such as high alcohol consumption (7), previously explained by adherence to healthhazardous masculinity norms (19).

It should be noted that the difference in mental well-being scores between non-care-seekers and care-seekers at T1 was small. However, even small differences may have major implications on population level given the high prevalence of depression, anxiety- and alcohol use disorders (1), and refraining from seeking mental healthcare among men $(6,24)$. In addition, this study only investigated differences in mental well-being among need-perceivers. However, a large proportion of men with depression do not perceive a need for care $(24,42)$. Potentially, this group may suffer from even poorer outcomes. Future studies should investigate differences in outcomes between need-perceivers and non-need-perceivers with a clinical need for care.

\section{Indication of poorer mental well-being among insufficient care-perceivers at T1}

Even in insufficient care-perceivers, the t-tests and the linear regression analysis showed poorer mental well-being at T1, compared to sufficient care-perceivers. However, this result was not statistically significant when controlling for sociodemographic and health variables (Table 3). This is probably due to the small sample in this sub-group analysis, as the sensitivity analysis on a larger sample showed a statistically significant difference (see Supplementary Table 3, Additional file 3). Our result is in line with previous research that has shown an association between dissatisfaction with care and depression $(34,35)$. The indicated poorer mental well-being among insufficient care-perceivers may be due to not receiving care of adequate quality (18), as consistent evidence shows a positive association between perceived sufficiency of care and quality of care (25). Another possible explanation is that insufficient care-perceivers were more sceptical about treatment due to masculinity norms, and therefore did not adhere to treatment (19). Masculinity norms have been shown to be a barrier to effective treatment also among care-seeking men (19). The healthcare system should help men to overcome these barriers by providing high-quality mental healthcare adapted to men's needs.

\section{No persistent differences in mental well-being at T2}

Although the expected differences in mental well-being between non-care-seekers and care-seekers, and insufficient care-perceivers and sufficient care-perceivers, were observed at T1, we found no differences at T2. This result is in line with previous studies showing that the majority of those with common mental disorders who do not seek treatment remit $(33,43,44)$. Results from a longitudinal study on men and women showed that among persons with untreated depression, anxiety or substance disorder, $50 \%$ remitted within three years (43). However, our results do not support any complete remission of symptoms, as both non-care-seekers and care-seekers (regardless of the perceived sufficiency of the care) still had mean mental well-being scores below the population mean at T2 (15.7, and 15.8, compared to the population mean 18.9). This is worrying, as the population mean should be the goal for complete remission (38). The lack of full recovery at T2 highlights a need for improved mental healthcare, but also a need to target other societal factors that may have greater importance for men's mental well-being. 
In sum, this study gives some empirical evidence to support the hypotheses of detrimental outcomes of refraining from seeking mental healthcare and of perceiving the care as insufficient when seeking it among men in Sweden. However, the relatively small differences at T1 and the lack of persistent differences at T2 point in another direction.

\section{Implications}

The small and non-persistent differences observed in this study could reflect a limited ability of the mental healthcare services to improve men's mental well-being. Other factors may be more important. Masculinity norms have previously been pointed out as the cause of men's reluctance to seek care, and other maladaptive coping strategies (7). WHO recently called for changes in masculinity norms on a societal level to improve men's mental well-being (45). To reach men there is a need for outreach strategies through media, workplaces, pubs, and sports associations. Changes in masculinity norms needs to be brought about in the healthcare system and in society (45). Changes in society will probably have a greater effect on men's mental well-being than focusing on mental healthcare only but both are important.

As men with common mental disorders are a heterogeneous group there is especially a need for an intersectional approach in the design of interventions and research $(45,46)$. Based on their social positions, some groups of men are more vulnerable to severe consequences (47), e.g. of not receiving treatment. This is indicated by our finding showing that non-care-seekers and insufficient care-perceivers born outside Nordic countries had poorer mental well-being than the corresponding groups born in Nordic countries, at both T1 and T2 (Table 2). However, these results were not statistically significant due to low statistical power in the stratified analysis. Future studies are needed, using larger populationbased samples that allow for intersectional analyses of differences among men.

\section{Methodological considerations}

This study has several limitations. Firstly, we cannot draw conclusions about causality. This is partly due to lack of data on the exact time of the exposures, i.e. when participants had refrained from seeking care, or perceived the care as insufficient, as the questions referred to "any time in life", but were measured at T1. Outcomes of not receiving treatment, e.g. poorer mental well-being, could therefore have occurred before T1. A reversed causality is also plausible, with those with poorer mental well-being at T1 being more likely to report receiving insufficient care due to general pessimism related to depression $(48,49)$. Secondly, we lack data on care-seeking between T1 and T2, which could explain the improved mental well-being of non-care-seekers and insufficient care-perceivers, as they may have sought and received sufficient care at T2. Thirdly, the participation rate of $34 \%$ may be problematic if participation was selective, e.g. if the association between the exposures and the outcome was stronger among non-participants. There is some research pointing in this direction. A Swedish study found that non-participating men were less likely to seek care (50). A Finnish study showed that non-participants were more likely to have a psychiatric disorder than participants (51). This is in line with our finding that those lost to follow-up were more likely to have poor mental well-being and persistent mental illness. However, we found no differences in care-seeking. Plausibly, non-participants share characteristics related to the study's exposures and outcomes, e.g. belonging to groups in adverse life situations who would benefit the most from treatment. Therefore, this study could have underestimated the negative effect of not receiving care. Fourthly, the relatively low participation rate, and the skewed participation based on sociodemographic characteristics (31) may have contributed to the limited statistical power in the adjusted and stratified analyses, leading to a risk of undetected true differences, i.e. a type II error.

In sum, due to these limitations the result should be generalised with caution. Future research with larger sample sizes, longer follow-up, and more refined methodology is needed. However, this study also has some relevant strengths, namely: 1) the relatively large population-based sample of men, 2) access to longitudinal data on mental well-being, 3) the use of the reliable and validated instrument WHO-10 (39, 40), and 4) stratified data on sociodemographic and health characteristics. In addition, this is one of the very few population-based studies investigating potential detrimental outcomes of not receiving sufficient mental healthcare among men.

\section{Conclusion}

This is the first longitudinal study on a population-based sample of men in Sweden investigating whether refraining from seeking mental healthcare, and perceiving care as insufficient when seeking it are detrimental to men's mental well-being. The current results show that refraining from seeking mental healthcare and perceiving the care as insufficient are potentially detrimental to men's mental well-being on a population level, but that the detrimental effect is limited in size and over time. Further longitudinal studies are needed, allowing sub-group analyses. In addition, we suggest interventions to increase men's mental healthcare-seeking and to provide mental healthcare that is perceived as sufficient. This cannot be done solely by the healthcare system. Instead, it must be done on a societal level by targeting health-hazardous masculinity norms that influence men's risk behaviours and perceptions about mental healthcare.

\section{Declarations}




\section{Ethics approval and consent to participate}

The HAP was conducted in accordance with the 1964 Declaration of Helsinki and its later amendments. Informed consent was obtained from all individual participants included in the study. The HAP was approved by the Ethics Committee, University of Gothenburg (registration number 03908).

\section{Consent for publication}

Not applicable.

\section{Availability of data and materials}

The data that support the findings of this study are available from the Swedish National Data Service, https://snd.gu.se/sv/catalogue/study/snd0870, but restrictions apply to the availability of this data.

\section{Competing interests}

The authors declare that they have no competing interests.

\section{Funding}

This study was funded by the Swedish Research Council for Health, Working Life and Welfare. The data collection for the HAP was financed by the Swedish Social Insurance Agency.

\section{Authors' contributions}

SO initiated the study design, performed the statistical analyses and wrote the first draft and main revisions of the manuscript. GH is PI for HAP responsible for the overall aim and data collection. All authors contributed to the study design, interpretation of data and critical revision of the manuscript, and approved the final version of the manuscript.

\section{Acknowledgement}

We would like to thank Anchor English for language editing assistance and Valter Sundh for advice on statistical analyses.

\section{References}

1. Wittchen H-U, Jacobi F, Rehm J, Gustavsson A, Svensson M, Jönsson B, et al. The size and burden of mental disorders and other disorders of the brain in Europe 2010. European Neuropsychopharmacology. 2011;21(9):655-79.

2. GBD Compare [Internet]. The Institute for Health Metrics and Evaluation (IHME),. [cited 2020, 9th July]. Available from: https://vizhub.healthdata.org/gbd-compare/

3. Kessler RC, de Jonge, P., Shahly, V., van Loo, H. M., Wang, P. S.-E., \& Wilcox, M. A. Epidemiology of depression. . In: Gotlib IH, Hammen CL, editors. Handbook of depression: Guilford Press; 2014. p. 7-24.

4. Craske MG, Stein MB. Anxiety. The Lancet. 2016;388(10063):3048-59. https://doi.org/10.1016/S0140-6736(16)30381-6

5. Malhi GS, Mann JJ. Depression. The Lancet. 2018;392(10161):2299-312. https://doi.org/10.1016/S0140-6736(18)31948-2

6. Wallerblad A, Möller J, Forsell Y. Care-seeking pattern among persons with depression and anxiety: A population-based study in Sweden. International Journal of Family Medicine. 2012;2012:895425. https://doi.org/10.1155/2012/895425

7. Möller-Leimkühler AM. The gender gap in suicide and premature death or: why are men so vulnerable? European archives of psychiatry and clinical neuroscience. 2003;253(1):1-8. https://doi.org/10.1007/s00406-003-0397-6

8. O'brien R, Hunt K, Hart G. 'It's caveman stuff, but that is to a certain extent how guys still operate': men's accounts of masculinity and help seeking. Social science \& medicine. 2005;61(3):503-16. https://doi.org/10.1016/j.socscimed.2004.12.008

9. Rutz W, Rihmer Z. Suicidality in men-practical issues, challenges, solutions. Journal of Men's Health and Gender. 2007;4(4):393-401. https://doi.org/10.1016/j.jmhg.2007.07.046

10. Courtenay WH. Key determinants of the health and well-being of men and boys. International Journal of Men's Health. 2003;2(1):1. 
11. White A, McKee M, Richardson N, de Visser R, Madsen SA, de Sousa BC, et al. Europe's men need their own health strategy. Bmj. 2011;343:d7397. https://doi.org/10.1136/bmj.d7397

12. Hale S, Grogan S, Willott S. Male GPs' views on men seeking medical help: a qualitative study. British Journal of Health Psychology. 2010;15(4):697-713. https://doi.org/10.1348/135910709X479113

13. Pirkis J, Spittal MJ, Keogh L, Mousaferiadis T, Currier D. Masculinity and suicidal thinking. Social Psychiatry and Psychiatric Epidemiology. 2017;52(3):319-27. https://doi.org/10.1007/s00127-016-1324-2

14. Cleary A. Suicidal action, emotional expression, and the performance of masculinities. Social Science \& Medicine. 2012;74(4):498-505. https://doi.org/10.1016/j.socscimed.2011.08.002

15. Kessler RC, Berglund P, Demler O, Jin R, Merikangas KR, Walters EE. Lifetime prevalence and age-of-onset distributions of dsm-iv disorders in the national comorbidity survey replication. Archives of General Psychiatry. 2005;62(6):593-602. https://doi.org/10.1001/archpsyc.62.6.593

16. Kessler RC, Demler O, Frank RG, Olfson M, Pincus HA, Walters EE, et al. Prevalence and treatment of mental disorders, 1990 to 2003 . New England Journal of Medicine. 2005;352(24):2515-23. https://doi.org/10.1056/NEJMsa043266

17. Johnson JL, Oliffe JL, Kelly MT, Galdas P, Ogrodniczuk JS. Men's discourses of help-seeking in the context of depression. Sociology of health \& illness. 2012;34(3):345-61. https://doi.org/10.1111/j.1467-9566.2011.01372.x

18. Thornicroft G, Chatterji S, Evans-Lacko S, Gruber M, Sampson N, Aguilar-Gaxiola S, et al. Undertreatment of people with major depressive disorder in 21 countries. British Journal of Psychiatry. 2017;210(2):119-24. https://doi.org/10.1192/bjp.bp.116.188078

19. Seidler ZE, Dawes AJ, Rice SM, Oliffe JL, Dhillon HM. The role of masculinity in men's help-seeking for depression: A systematic review. Clinical Psychology Review. 2016;49:106-18. https://doi.org/10.1016/j.cpr.2016.09.002

20. Rutz W, von Knorring L, Pihlgren H, Rihmer Z, Wålinder J. Prevention of male suicides: lessons from Gotland study. The Lancet. 1995;345(8948):524. https://doi.org/10.1016/S0140-6736(95)90622-3

21. Bertakis KD, Helms LJ, Callahan EJ, Azari R, Leigh P, Robbins JA. Patient gender differences in the diagnosis of depression in primary care. Journal of women's health \& gender-based medicine. 2001;10(7):689-98. https://doi.org/10.1089/15246090152563579

22. Sundbom LT, Bingefors K, Hedborg K, Isacson D. Are men under-treated and women over-treated with antidepressants? Findings from a cross-sectional survey in Sweden. BJPsych Bulletin. 2017;41(3):145-50. https://doi.org/10.1192/pb.bp.116.054270

23. Øyeflaten I, Maeland S, Haukenes I. Independent medical evaluation of general practitioners' follow-up of sick-listed patients: a crosssectional study in Norway. BMJ open. 2020;10(3):e032776. https://doi.org/10.1136/bmjopen-2019-032776

24. Olsson S, Hensing G, Burström B, Löve J. Unmet need for mental healthcare in a population sample in Sweden: A cross-sectional study of inequalities based on gender, education, and country of Birth. Community Mental Health Journal. 2020:1-12. https://doi.org/10.1007/s10597-020-00668-7

25. Doyle C, Lennox L, Bell D. A systematic review of evidence on the links between patient experience and clinical safety and effectiveness. BMJ open. 2013;3(1):e001570. http://dx.doi.org/10.1136/bmjopen-2012-001570

26. Kessler RC, Berglund P, Demler O, Jin R, Koretz D, Merikangas KR, et al. The epidemiology of major depressive disorder: results from the National Comorbidity Survey Replication (NCS-R). Jama. 2003;289(23):3095-105. https://doi.org/10.1001/jama.289.23.3095

27. Yousaf 0 , Grunfeld EA, Hunter MS. A systematic review of the factors associated with delays in medical and psychological help-seeking among men. Health psychology review. 2015;9(2):264-76. https://doi.org/10.1080/17437199.2013.840954

28. Glenngård AH. The Swedish health care system, 2015. In: Mossialos E, Wenzl M, Osborn R, Sarnak D, editors. 2015 International Profiles of Health Care Systems: The Commonwealth Fund; 2016.

29. Holmgren K, Hensing G, Dellve L. The association between poor organizational climate and high work commitments, and sickness absence in a general population of women and men. Journal of occupational and environmental medicine. 2010;52(12):1179-85. https://doi.org/10.1097/JOM.0b013e3181fc5c1a

30. Hensing G, Holmgren K, Mårdby AC. Harmful alcohol habits were no more common in a sample of newly sick-listed Swedish women and men compared with a random population sample. Alcohol and Alcoholism. 2011;46(4):471-7. http://dx.doi.org/10.1093/alcalc/agr033

31. Knapstad M, Löve J, Holmgren K, Hensing G, Øverland S. Registry-based analysis of participator representativeness: a source of concern for sickness absence research? BMJ open. 2016;6(10):e012372. https://doi.org/10.1136/bmjopen-2016-012372

32. Hansson A, Hillerås P, Forsell Y. Well-Being in an adult Swedish population. Social Indicators Research. 2005;74(2):313-25. https://doi.org/10.1007/s11205-004-6168-6

33. Boerema A, Ten Have M, Kleiboer A, de Graaf R, Nuyen J, Cuijpers P, et al. Demographic and need factors of early, delayed and no mental health care use in major depression: a prospective study. BMC psychiatry. 2017;17(1):367. https://doi.org/10.1186/s12888-017-1531-8

34. Bui Q-UT, Ostir GV, Kuo Y-F, Freeman J, Goodwin JS. Relationship of depression to patient satisfaction: findings from the barriers to breast cancer study. Breast cancer research and treatment. 2005;89(1):23-8. 
35. Lee DS, Tu JV, Chong A, Alter DA. Patient satisfaction and its relationship with quality and outcomes of care after acute myocardial infarction. Circulation. 2008;118(19):1938-45. https://doi.org/10.1161/CIRCULATIONAHA.108.792713

36. Hansson A. Subjective well-being in an adult Swedish population: Findings from a population-based study. Stockholm, Sweden: Karolinska Institutet; 2009.

37. Hansson A, Hillerås P, Forsell Y, Lundberg I. The WHO (Ten) well-being index as a screening instrument for major depression in a populationbased sample. European Psychiatry. 2007;22, Supplement 1:S314-S5. https://doi.org/10.1016/j.eurpsy.2007.01.1046

38. Topp CW, Østergaard SD, Søndergaard S, Bech P. The WHO-5 Well-Being Index: A systematic review of the literature. Psychotherapy and Psychosomatics. 2015;84(3):167-76. https://doi.org/10.1159/000376585

39. Bech P, Gudex C, Staehr Johansen K. The WHO (Ten) well-being index: validation in diabetes. Psychotherapy and psychosomatics. 1996;65(4):183-90. https://doi.org/10.1159/000289073

40. Löve J, Andersson L, Moore CD, Hensing G. Psychometric analysis of the Swedish translation of the WHO well-being index. Quality of Life Research. 2013;23(1):293-7. https://doi.org/10.1007/s11136-013-0447-0

41. Fidell L, Tabachnick B. Using multivariate statistics (New International Edition ed.). London: Pearson; 2014.

42. Codony M, Alonso J, Almansa J, Bernert S, Giovanni de Girolamo M, de Graaf R, et al. Perceived need for mental health care and service use among adults in Western Europe: results of the ESEMeD project. Psychiatric Services. 2009;60(8):1051-8.

https://doi.org/10.1176/ps.2009.60.8.1051

43. Sareen J, Henriksen CA, Stein MB, Afifi TO, Lix LM, Enns MW. Common mental disorder diagnosis and need for treatment are not the same: findings from a population-based longitudinal survey. Psychological Medicine. 2013;43(9):1941-51. https://doi.org/10.1017/S003329171200284X

44. Wang Y, Henriksen CA, Ten Have M, de Graaf R, Stein MB, Enns MW, et al. Common mental disorder diagnosis and need for treatment are not the same: findings from the NEMESIS study. Administration and Policy in Mental Health and Mental Health Services Research. 2017;44(4):572-81. https://doi.org/10.1007/s10488-016-0745-2

45. The health and well-being of men in the WHO European Region: better health through a gender approach [Internet]. 2018 [cited 2020 , 9 th July]. Available from: https://www.euro.who.int/en/publications/abstracts/the-health-and-well-being-of-men-in-the-who-european-regionbetter-health-through-a-gender-approach-2018

46. White A, Richardson N. Gendered epidemiology: making men's health visible in epidemiological research. public health. 2011;125(7):407-10. https://doi.org/10.1016/j.puhe.2011.04.012

47. Diderichsen F, Andersen I, Manuel C, Working Group of the Danish Review on Social Determinants of Health, Andersen A-MN, Bach E, et al. Health Inequality-determinants and policies. Scandinavian journal of public health. 2012;40(8_suppl):12-105.

https://doi.org/10.1177\%2F1403494812457734

48. Morgado A, Smith M, Lecrubier Y, Widlöcher D. Depressed subjects unwittingly overreport poor social adjustment which they reappraise when recovered. Journal of Nervous and Mental Disease. 1991. https://doi.org/10.1097/00005053-199110000-00005

49. Alonso J, Angermeyer MC, Bernert S, Bruffaerts R, Brugha TS, Bryson H, et al. Disability and quality of life impact of mental disorders in Europe: results from the European Study of the Epidemiology of Mental Disorders (ESEMeD) project. Acta Psychiatrica Scandinavica. 2004;109(s420):38-46. https://doi.org/10.1111/j.1600-0047.2004.00329.x

50. Agerholm J, Bruce D, Burström B. Comparing healthcare utilization among health survey respondents with the total population - are respondents representative? BMC Health Services Research. 2016;16(1):510. https://doi.org/10.1186/s12913-016-1745-3

51. Haapea M, Miettunen J, Läärä E, Joukamaa MI, Järvelin M-R, Isohanni MK, et al. Non-participation in a field survey with respect to psychiatric disorders. Scandinavian Journal of Public Health. 2008;36(7):728-36. https://doi.org/10.1177/1403494808092250

\section{Figures}




\section{Exposures at any time in life}

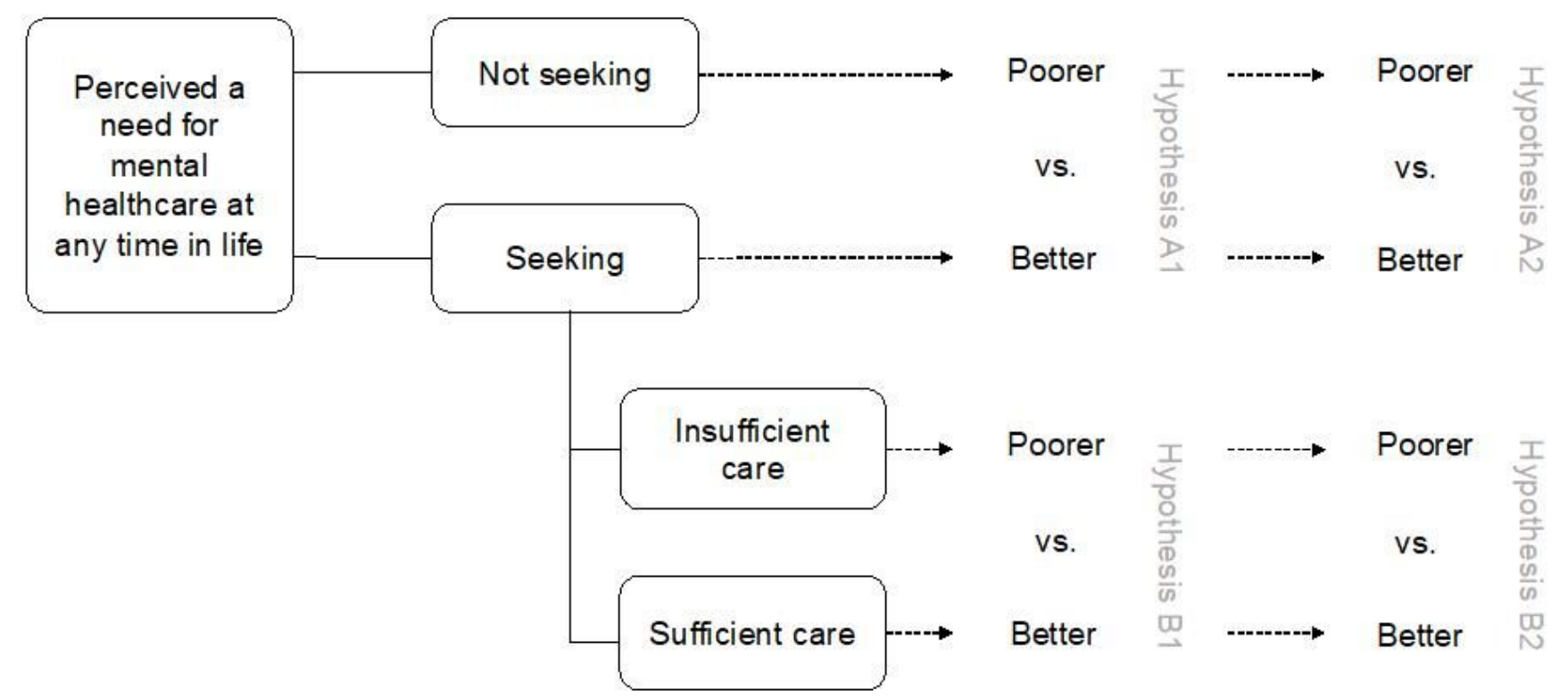

Outcome: Mental well-being

Time 1, 2008

Time 2, 2009

\section{Figure 1}

Hypotheses and study design

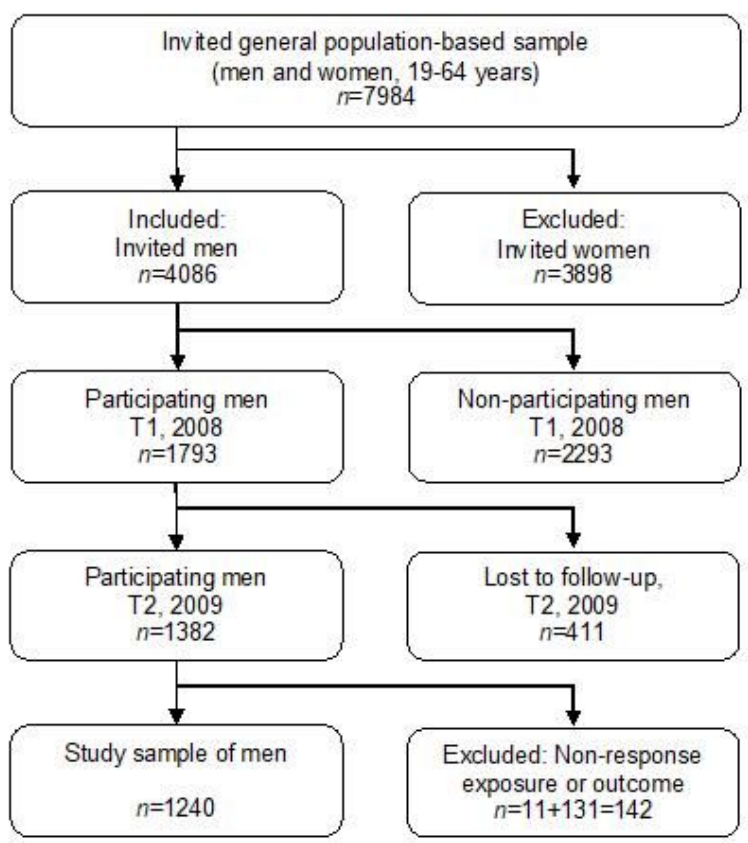

Figure 2

Flow chart of the study sample of men.

\section{Supplementary Files}

This is a list of supplementary files associated with this preprint. Click to download.

- Additionalfile3.docx

- Additionalfile2.docx 
- Additionalfile1.docx

Page 15/15 